Fisheries Research

January 2017, Volume 185 Pages 73-82

http://dx.doi.org/10.1016/j.fishres.2016.10.003

http://archimer.ifremer.fr/doc/00355/46605/

(c) 2016 Elsevier B.V. All rights reserved.

\title{
Assessing the number of moored fishing aggregating devices through aerial surveys: A case study from Guadeloupe
}

\author{
Guyader Olivier ${ }^{1,{ }^{*}}$, Bauer Robert ${ }^{2}$, Reynal Lionel ${ }^{3}$
}

\author{
${ }^{1}$ Ifremer, Univ Brest, CNRS, UMR 6308, AMURE, Unité d'Economie Maritime, IUEM, F-29280 \\ Plouzane, France \\ ${ }^{2}$ Ifremer, UMR Marbec, Avenue Jean Monnet, CS 30171, 34203 Sète Cedex, France \\ ${ }^{3}$ Ifremer, Unité Biodiversité et Environnement, Département Ressources Biologiques et Environnement \\ (RBE), Délégation de Martinique 79 Route de Pointe-Fort, 97231 Le Robert, Martinique
}

*Corresponding author : Olivier Guyader, email address : oguyader@ifremer.fr

\begin{abstract}
:
Moored fish aggregating devices (MFADs) are increasingly being used in small-scale tropical fisheries to access pelagic fish species that are otherwise difficult to harvest in large numbers. Little attention has yet been paid to monitoring MFADs in coastal areas, however. This is most likely due to the small-scale nature of most fisheries that utilize them and the presumed lower impact of those fisheries on fish stocks and their ecosystems. In this paper, we examined the abundance and density of MFADs around Guadeloupe, using aerial line transect surveys. Estimated MFAD densities were found to be high compared with previously reported densities in this area, especially within the 22-45 km range offshore. We examine and discuss possible reasons for these high densities. The main drivers appear to be the target species dolphinfish (Coryphaena hippurus) and yellowfin tuna (Thunnus albacares) and related fishing behaviour. We present different approaches for reducing and monitoring MFADs densities, including the co-management of MFAD territorial use rights by fishing communities.
\end{abstract}

Keywords: Small-scale fisheries management, Dolphinfish, Yellowfin tuna, Aerial survey, Fish aggregating devices (FAD) 


\section{Introduction}

In many parts of the world, including the Caribbean, moored fish aggregating devices (MFADs, also called anchored fish aggregating devices) are used by small-scale fishermen to access fish species that are otherwise difficult to harvest in large numbers (Gomes et al., 1998; Rey-Valette et al., 2000; Taquet et al., 2011). Such devices are man-made structures designed to float on or near the surface in order to attract fish and thus facilitate their capture (Dempster and Taquet, 2004). An MFAD is generally made of a buoy or set of linked buoys of different sizes and colours that are attached to the seafloor with a mooring rope and a block of concrete or steel. The length of the rope depends on the depth of the water where the MFAD is set, and can vary between 200 and 5000 m (Gervain et al., 2015). In order to increase fish aggregations around an MFAD, additional devices are often tied to the rope at the surface or sub-surface in order to attract fish. In Guadeloupe, fishermen commonly use pieces of trawling nets, plastic sheeting or polypropylene lashing straps, which also prevent trolling lines from becoming hooked onto the devices.

MFADs have several benefits as they create known targetable fishing resource patches, which significantly reduce search time, effort, and fuel costs for fishermen. MFAD development programs are also seen as a way to improve catch rates and, thus, the income and livelihoods of local fishing communities. They may also help to reduce fishing pressure on coastal species by concentrating fishing effort on offshore pelagic fish stocks (Taquet et al., 2011). 
In contrast, drifting FADs (DFADs), which are equipped with GPS tracking devices, are mainly deployed by large offshore fleets that target tropical tunas, but also catch other species that aggregate around DFADs, e.g., dolphinfish (Coryphaenidae), wahoo (Acanthocybium solandri), blue marlin (Makaira nigricans) and various triggerfish species (Amande et al., 2010). Increasing use of DFADs in recent years has raised concerns about their ecological impact (Dagorn et al., 2012). It is now recognized that the quantity and location of DFADs needs to be managed in order to ensure that they can be used in a sustainable manner (Davies et al., 2014). While the number of DFADs has increased in the Atlantic recently, their exact number is difficult to estimate (Fonteneau et al., 2015).

The literature has so far focussed very little on the management of MFADs in coastal areas. This is most likely due to the small-scale nature of most of the fisheries that utilize them in this way, and the presumed lower impact of those fisheries on fish stocks and their ecosystems. Indeed, the deployment of MFADs and evolution of associated fisheries is rarely documented (Taquet et al., 2011). However, this information is needed to assess the impact of MFADs on fish stocks (e.g., reduction of tuna aggregation capacity per FAD (Holland et al., 1990; Cayré, 1991; Dagorn et al., 2000)) and the benefits they offer to local fishing communities (e.g., incomes, food supply, etc.). For example, MFAD densities might affect catch rates, which are used to assess temporal changes in the abundance of the resources (Dagorn et al., 2012). Although MFADs are monitored in some countries, for example the Maldives (MFA, 2016) or La Réunion (CRPMEM, 2015), no monitoring program on private or public MFADs exists in the Caribbean area (Ramdine, 2007). Such information could be obtained through government actions (Anderson and Gates, 1996), such as by monitoring 
MFAD installation programs or establishing regulations requiring fishermen or fishing authorities to report the deployment of MFADs.

In the case of Guadeloupe (FAO area 31), private MFADs have been being installed since the beginning of the 1990s without any accurate knowledge of their number or location (Diaz, 2007; Guyader et al., 2013). This fishery expanded in the 1990s, with an increasing number of vessels and an extension of fishing areas from coastal waters to more distant areas (Mathieu et al., 2013). Of the 767 vessels active in Guadeloupe in 2008, 282 units were involved in MFAD fishing, with total landings of 1600 tons having a value of approximately 13 million Euros (Guyader et al., 2013). The number of active vessels has remained almost stable since the mid-2000s. Most of these local fishing vessels are between 7 and $9 \mathrm{~m}$ in length and open-decked with powerful outboard engines. Fishing is mainly done by trolling and drifting vertical longlines around MFADs (Diaz et al. 2005; Taquet et al., 2000). The main target species are dolphinfish (Coryphaena hippurus) (61\%), yellowfin tuna (Thunnus albacares) (18\%), blue marlin (Makaira nigricans) (8\%), triggerfish (Canthidermis maculatus) (7\%) and other miscellaneous species like wahoo (Acanthocybium solandri), rainbow runner (Elagatis bipinnulata) and other tunas (Guyader et al., 2014). The structure of fish aggregations around MFADs in the Lesser Antilles was characterized acoustically by Doray et al. (2006).

These commercial species are highly migratory and widely distributed in the Atlantic intertropical area, including the Caribbean Sea, for which Guadeloupe provides only a small proportion of the total catches. According to the Caribbean Regional Fisheries Mechanism (2010), there is no evidence for a decline in the local dolphinfish stock at current harvesting 
levels. However, CRFM recommends that a precautionary approach should be adopted in managing this fishery. By contrast, yellowfin tuna stocks are considered by the International Commission for the Conservation of Atlantic Tunas to be fully exploited in this area, while it recommends that blue marlin needs the balance of its stocks to be strengthened (ICCAT, 2014). In summary, the current state of the different fish stocks targeted by the MFADfishery around Guadeloupe further highlights the need to improve the current monitoring and management of this fishery and other MFAD fisheries in the Caribbean.

According to MFAD regulations in Guadeloupe, MFADs can be installed by commercial fishermen after authorization has been granted by the local maritime authorities (Prefectural Order, 2002). These regulations also require that fishermen equip MFADs with maritime signalling systems and report their exact positions and characteristics, as well as the identification of the fishermen operating around them. However, the quality of this information is considered to be very poor because it is difficult to enforce this regulation (Guyader et al., 2013). Underreporting of MFAD deployments is a serious issue for fishery management. Given that MFAD losses are not registered, it is almost impossible to know the real number of MFADs in use in this fishery.

To alleviate the drawbacks of this weakly-regulated private MFAD system, in 2008 and 2009, local fishing organizations decided, with the support of the local administration and public funds, to establish a network of collective MFADs within a 24-nm zone around Guadeloupe (Gervain and Diaz, 2011). The main objectives of this network were: 1) to reduce the number of MFADs and potential interactions between them, 2) to encourage fishermen to better coordinate their fishing activities around MFADs, and 3) to reduce the risk of interactions 
with other activities (e.g., maritime transport) and ecosystem impacts associated with the loss of MFADs (Diaz et al., 2005). At this time, 40 MFADs have been set around Guadeloupe with a distance range of 5-12 $\mathrm{nm}$ between them, considering the scientific literature on the size of tuna-FAD interaction zones. However, this network of collective MFADs was not successful and few of these MFADs were still in place in 2012, further highlighting the requirement for a new and fishery-independent assessment of the number of MFADs deployed around Guadeloupe.

The objective of this paper is to provide fishery-independent estimates of the number and density of MFADs around Guadeloupe through aerial line transect surveys. Line transect surveys are a common technique for monitoring animal abundance in terrestrial and aquatic wildlife management (Buckland, 2001). Aerial line transect surveys have been applied to assess the abundance of marine mammals, sea turtles and surfacing fish, including whale sharks and Atlantic bluefin tuna (Rowat et al., 2009; Fortuna et al., 2014; Bauer et al., 2015). They may also represent a suitable tool to survey the spatial distribution and densities of MFADs independently of fishermen's reports. A pilot aerial survey, carried out in 2008 in Guadeloupe, showed promising results for such an application and further suggested that the number of MFADs in this area was actually higher than thought by fisheries authorities (Guyader et al., 2011). We also sought to improve our understanding of differences in MFAD fisheries in the Caribbean by comparing abundance and density estimates obtained in this study with preliminary estimates from nearby regions. In this context, we examined different factors that could structure the deployment of MFADs around Guadeloupe (e.g., anchorage depth, distance to closest port and next nearest MFAD, fishing behaviour and target 
species). Different approaches to reduce and monitor MFAD densities are discussed, including the co-management of MFAD territorial use rights by fishing communities. 


\section{Methods}

\subsection{Aerial line transect surveys in Guadeloupe}

Guadeloupe, in the Lesser Antilles, is a French overseas territory comprising the islands of Grande-Terre and Basse-Terre and several smaller islands in the Leeward Islands (Fig. 1).

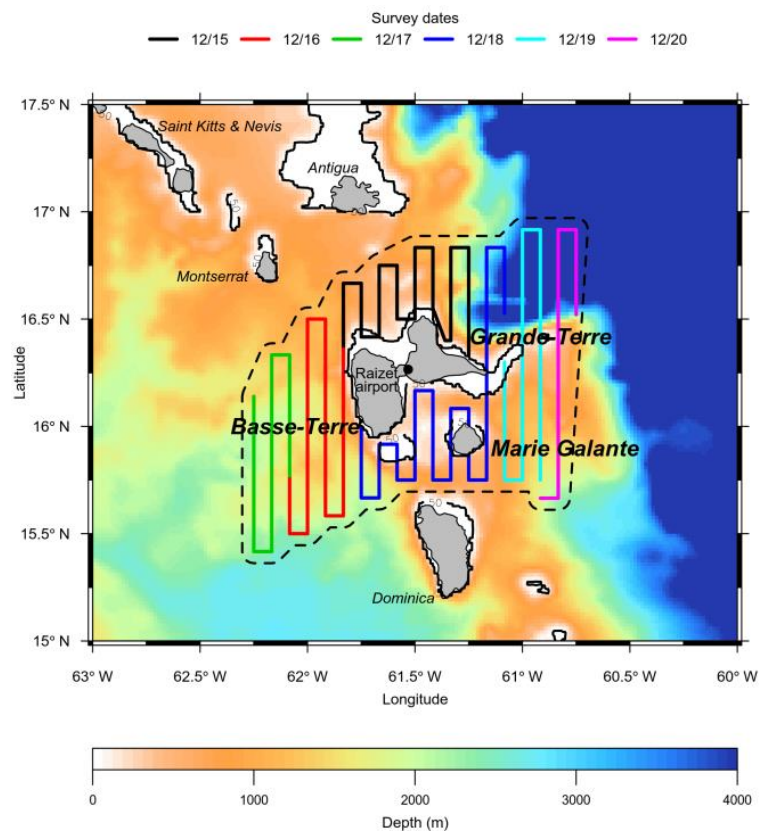

Fig. 1. Bathymetry around Guadeloupe with the survey area (dashed line; $18851.7 \mathrm{~km}^{2}$ in size), starting airport (dot) and transects covered per survey date visualized using the Rpackage "oceanmap" (Bauer, 2016). Note that horizontal and diagonal transect lines are offeffort and not considered in the line transect modelling and the estimation of encounter rates. The $50 \mathrm{~m}$ contour line is given as reference for later analyses (density and abundance estimation of MFADs).

Aerial surveys were carried out in Guadeloupe in 2012 during the month of December, a period of the year when conditions are usually particularly suitable for such surveys. Unlike the January-June period, when strong trade winds blow over the Caribbean Sea, AugustDecember is characterized by tropical depressions interspersed by periods of low wind. June 
to July is not suitable for surveys because of strong currents, which increasing the risk of MFADs sinking. Line transects (102-104 km in length) were spaced at $8.9 \mathrm{~km}$ and orientated in the North-South direction, irrespective of the bathymetry or fishing effort data of the survey region. A Cessna 72 aircraft, without bubble windows, was chartered from Raizet airport (Fig. 1), flown by the same pilot, but employing slightly changing teams of three trained scientific observers (one in the front, two at the back) for the survey. In accordance with the limitations of the aircraft's fuel capacity, the transects were split into 6 sections, which were then each surveyed within 1:45-3:30 hours over 6 consecutive days (15-20th December 2012).

Flights were conducted at around $300 \mathrm{~m}$ with an average travelling speed of $170 \mathrm{~km} \mathrm{~h}^{-1}$. An on-board GPS registered the position of the aircraft every second, while waypoints of sighted MFADs were logged manually by one of the observers. For these recordings, the aircraft was required to leave and return to the transect line. Perpendicular distances between MFAD locations and the transect lines were then calculated based on the actual flight paths, disregarding off-route excursions. Pictures of each sighted MFAD were systematically recorded to later test the effects of MFAD characteristics on MFAD detectability. Sighting conditions, i.e. rainfall, cloud coverage (\%), sea state (swell), and wind speed (knots) and direction were recorded at the beginning of each flight and when changes were noted. MFADs fishing effort data per area from the Ifremer fisheries information system was also used to compare with the estimated MFAD distribution (see Guyader et al; 2013 for a description). 


\subsection{Data processing}

Pictures of each sighted MFAD were examined and processed to provide different metrics about their characteristics. This included the number of buoys per MFAD, the total surface area of buoys (considering the estimated diameter of each), the surface area of the buoys per colour and the overall length of the MFAD $(m)$ visible at the sea surface. The product catalogue of the main ship chandlery for fishermen on the island was also used to calculate the sizes and identify the colours of each buoy type. The accuracy of such estimates was improved by information from three fishermen, especially for the identification of buoy type and MFAD length. The fishermen were chosen for their experience in MFAD fishing and came from the western, northern and north-eastern coasts of Guadeloupe. These fishermen also provided qualitative information of the design rationale and personal opinions on the advantages and disadvantages of each MFAD.

We further examined the colour composition of MFADs based on the average surface area (\%) occupied by buoys of different colours. As an additional source for sighting conditions, Windguru historical database was used at a $3 \mathrm{~h}$ resolution for the following variables (http://www.windguru.cz/fr/historie.php): wind (knots) and wind sector (degree), swell (m), wave period $(\mathrm{m})$, rain $(\mathrm{mm} / 3 \mathrm{~h})$ and cloud coverage (\%). The Marie-Galante wind station

(Fig. 1) was used as it was considered to be the most representative of weather conditions at the surrounding sea.

Based on the sighting data, we calculated encounter rates for each survey date. To estimate MFAD abundance in the survey area, we then applied conventional distance sampling (CDS) 
and multiple-covariate distance sampling approaches (MCDS; Marques and Buckland, 2004) as implemented in the R-package "mrds". These methods estimate the decline in detection probability with increasing distance to the transect line, with the latter accounting for possible covariates. In this context, we tested all possible combinations of potential covariates recorded during the aerial surveys, including observer team, sea state (swell), MFAD size and colour combination. To avoid outliers and thus facilitate modelling, we truncated $9 \%$ of the largest perpendicular distances $(\geq 3 \mathrm{~km})$ in accordance with common practice (Buckland, 2001). This was done after visual inspection of the sighting data and was cross-validated during the modelling process. Without bubble windows, visibility can be reduced beneath the aircraft and thus lead to a lack of detections in the area close to the transect line. As such effects impair the modelling of the detectability, sighting frequencies are often left-truncated (Buckland, 2001). However, our data did not indicate a lack of MFAD-detections close to the transect line. We therefore did not left-truncate our data . Horizontal and diagonal transect sections were off-effort and not considered in the modelling. Moreover, as the survey on the fourth day (18th December 2012) was highly impaired by bad weather conditions, data from this route was excluded from the analysis

(Fig. 1). Models were then selected based on the Akaike's information criterion (AIC) and further evaluated using goodness of fit tests (q-q plots, Cramer-von Mises and KolmogorovSmirnov, and Chi-square tests; Buckland, 2004). MFAD abundance was then calculated based on the proportion of the survey area with depths greater than $50 \mathrm{~m}$ (Fig. 1).

\subsection{Spatial densities of MFADs}


In order to get an idea of the spatial distribution of MFAD deployment in the survey area, we applied the fixed kernel density estimation algorithm to interpolate between sighting locations (Worton, 1989). To do this, we applied a bivariate normal kernel, given by the "kde2d" function from the R-package "MASS" (Venables and Ripley, 2002), thereby interpolating sighting locations on a square grid of $1000 \times 1000$ points (resolution: $321 \times 277$ $\mathrm{m}$ ) with a bandwidth (search radius) of 0.5 degrees. This radius is around 12.5 times the average inter-transect distance $(8.9 \mathrm{~km})$, facilitating the interpolation between distant sighting locations. The kernel density estimates thus obtained were converted to percentages to facilitate interpretation of the results.

\subsection{Strategic elements in MFAD deployment}

Different factors may influence fishermen in their selection of MFAD deployment sites and densities. As potential factors, we investigated the anchorage depth and distances to the closest port and next MFAD. To examine the anchorage depth of sighted MFADs, the bathymetry of the survey area was obtained at a spatial resolution of $0.5 \mathrm{~min}$ from the ETOPO1 bathymetry database hosted by NOAA (Amante and Eakins, 2009). In order to calculate the distance to the closest port, we considered 18 major Guadeloupe fishing ports on Basse-Terre, Grande-Terre, La Désirade, Marie Galante and Les Saintes islands, disregarding fishing ports on surrounding foreign islands as only fishermen from Guadeloupe are permitted to fish in the survey area. The distance to the closest port was then mapped by estimating this distance for each point of a $200 \times 200$ point square grid, using the function "distHaversine" of the R-package "geosphere" (Hijmans, 2015). Both maps (bathymetry and distance to closest port) were then sampled using the GPS locations of the sighted MFADs. In 
order to compare the thus obtained datasets with the respective theoretical distributions, line transects were split into series of points spaced by $100 \mathrm{~m}$. These points were then used as sampling locations for the two mapped parameters. The distance to the next MFAD was also estimated with the "distHaversine"-function, based on MFAD sighting locations from all survey dates (including off-effort sightings). Theoretical distances to next closest MFAD were calculated based on simulated MFAD distributions that considered the actual MFADencounter rates observed per transect (ER).

\section{Results}

A total of 99 MFADs were detected during the line transect aerial surveys conducted in the period 15-20th December 2012 in the waters around Guadeloupe. Sighting locations revealed spatial heterogeneity in MFAD deployment sites, with higher densities found in the NE- and SW-waters around Guadeloupe. Easily accessible sites for MFAD deployment seem to be avoided by fishermen.

\subsection{MFAD characteristics}

The MFADs sighted in this study were composed of single to multiple buoys (Fig. 2) and were different colours. Single-buoy MFADs were particularly frequent, and many were located in the north-eastern part of the survey area. Only a few MFADs comprised more than 10 buoys (11.6\%). Most buoys making up the sighted MFADs were in yellow, orange, white or red, which corresponds to the buoy colours that are the easiest to find in ship chandleries. Only a few buoys were blue, grey or green. Fishermen did not report any relation between buoy 
colour and attractiveness to fish, but mentioned that blue and grey may reduce MFAD detection by other fishermen. The number of buoys can be increased with the aim of improving the MFAD floatability. Recently, fishermen have built fiberglass mono-buoys to have the required floatability. Some fishermen stated that mono-buoys reduce their aggregation capacity, which is why they add additional devices to their MFADs, but this is not considered useful by all.
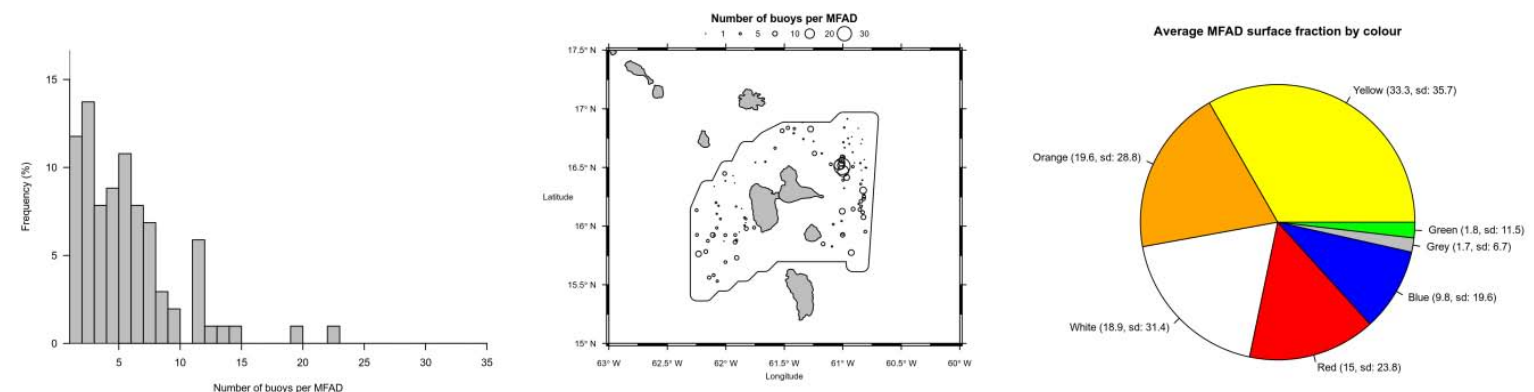

Fig. 2. Number of buoys per MFAD (left) with respective locations (middle), as well as the average surface area of different colours per MFAD based on buoy surface area estimates per colour (right). In the map (middle panel), the solid line indicates the survey area around Guadeloupe.

\subsection{MFAD density and abundance estimates}

MCDS models did not perform significantly better than the CDS model with a half normal key-function (AIC difference < 2), although the best MCDS model indicated effects of the observer team and sea state. All goodness of fit tests (qq-plot, Chi-square, Cramer-von Mises and Kolmogorov-Smirnov tests) produced good results for the CDS model ( $p>0.05$ ). Density and abundance estimates were therefore calculated using the CDS fit (Fig. 3). This fit suggests a constant detection probability of 0.48 during all surveys made, corresponding to 
an effective strip half-width (ESW) of $1.44 \mathrm{~km}$ (inside which as many MFADs were spotted, as were missed outside).

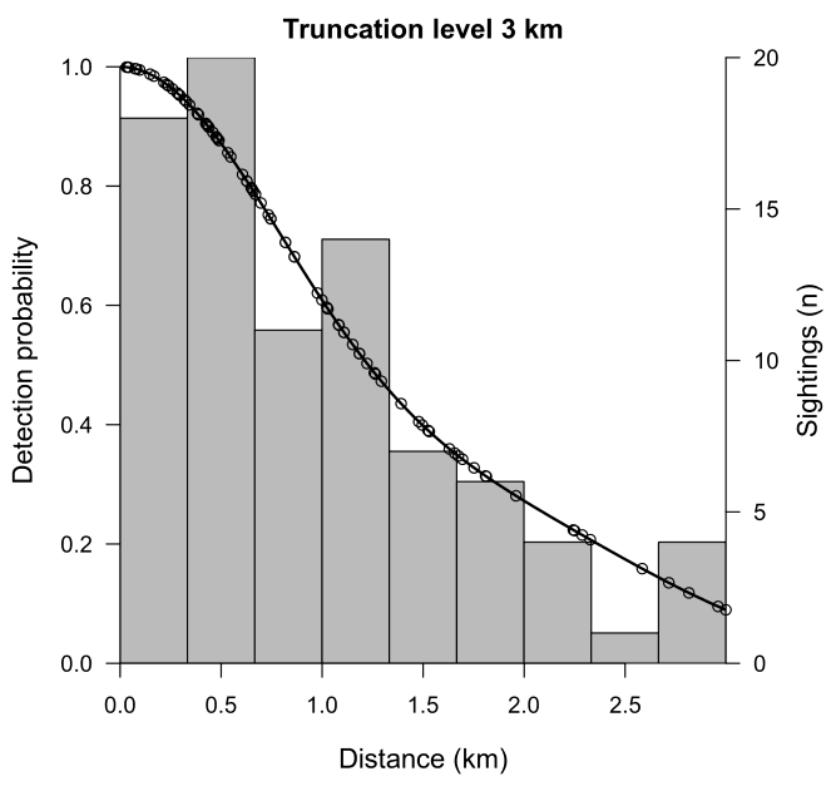

Fig. 3. Sighting frequencies and estimated detection probabilities (black line) of MFADs per distance during the Guadeloupe aerial surveys. Dots represent fitted detection probabilities for individual sightings.

The density of MFADs in the survey region was estimated to be 2.1 MFADs per $100 \mathrm{~km}^{2}$, but ranged between 1-3.6 MFADs per $100 \mathrm{~km}^{2}$ during the survey dates (Table. 1). This corresponds to a total number of 404 MFADs (95\% Cl: $241.3-676.3)$ if extrapolated to the survey region. For comparison, 4-30 MFADs were detected per survey date/route (99 MFADs in total) with a sighting rate (encounter rate) of 1-9 MFADs per $100 \mathrm{~km}$. 
Tab. 1: MFAD density and abundance estimates based on CDS for each survey repetition and the total survey area. Effort = on-effort transect length $(\mathrm{km})$, Covered Area = surveyed oneffort area (in $\mathrm{km}^{2}$, calculated by twice the product of the on-effort transect length and the truncation distance of $3 \mathrm{~km}$ ), Area = Total survey area (in $\mathrm{km}^{2}$, as shown in Fig. 1 , or its fraction relative to the size of the covered area per survey date (covered area/total survey area), $n=$ number of sighted MFADs (after truncation), ER = encounter rate ( $\mathrm{n} / \mathrm{km}$ transect), $\mathrm{D}=$ estimated MFAD density $\left(\mathrm{n} / \mathrm{km}^{2}\right), \mathrm{N}=$ estimated MFAD abundance, $\mathrm{Cl}=$ confidence interval, and CV = coefficient of variation.

\begin{tabular}{rrrrrrcrrrr}
\hline Survey dates & Effort & Covered Area & Area & \multicolumn{1}{c}{$\mathrm{n}$} & ER & $\mathrm{D}$ & $95 \% \mathrm{Cl}(\mathrm{D})$ & $\mathrm{N}$ & $95 \% \mathrm{Cl}(\mathrm{N})$ & $\mathrm{CV}(\%)$ \\
\hline $2012-12-15$ & 299,9 & 1798,6 & 3168,4 & $12(9)$ & 0,032 & 0,010 & $0.005-0.022$ & 33,1 & $15.8-69.3$ & 22,5 \\
$2012-12-16$ & 329,9 & 1978,3 & 3485,0 & $21(19)$ & 0,059 & 0,020 & $0.013-0.032$ & 69,8 & $44.2-110.3$ & 18,6 \\
$2012-12-17$ & 245,3 & 1471,0 & 2591,2 & $14(12)$ & 0,053 & 0,017 & $0.009-0.031$ & 44,1 & $24.2-80.2$ & 20,7 \\
$2012-12-18$ & 405,1 & 2430,9 & 4280,0 & $4(0)$ & 0,010 & & & & & \\
$2012-12-19$ & 320,9 & 1924,3 & 3389,8 & $30(26)$ & 0,089 & 0,028 & $0.019-0.042$ & 95,5 & $64.1-142.4$ & 17,5 \\
$2012-12-20$ & 183,4 & 1099,8 & 1937,4 & $22(19)$ & 0,109 & 0,036 & $0.023-0.057$ & 69,8 & $44.2-110.3$ & 18,6 \\
\hline Total & 1379,4 & 8272,1 & 18851,7 & $99(85)$ & 0,065 & 0,021 & $0.013-0.036$ & 404,0 & $241.3-676.3$ & 23,4 \\
\hline
\end{tabular}

\subsection{Spatial distribution of MFADs}

Kernel densities showed two core areas of MFAD deployment (Fig. 4), which are located to the NE and SW of Guadeloupe. The north-eastern area appears thereby to be more important. It is situated at the edge of the continental slope region, where currents are also more pronounced (data not shown). Fishing effort data of the survey region agrees quite well with the estimated MFAD distribution, with higher fishing effort being visible in areas of high MFAD density (Fig. 4). 

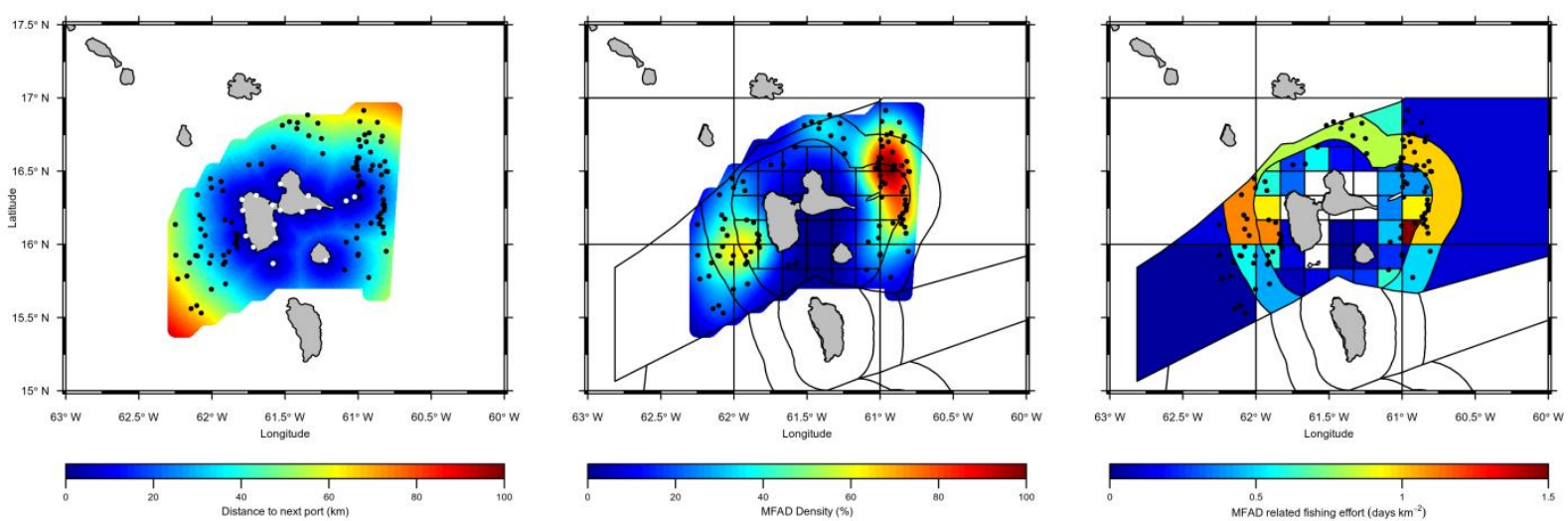

Fig. 4. Maps of MFAD distance to nearest port (left) with considered port locations (white dots) and the survey area, as well as MFAD kernel densities with management strata (middle), and fishing effort per management strata (right panel). Black dots indicate MFAD sighting locations.

\subsection{Strategic elements in MFAD deployment}

The estimated anchorage depth of sighted MFADs ranged between 190 and 5,671 m (mean: $2010 \mathrm{~m}$ ). The corresponding distribution showed a strong peak at 1,000 $\mathrm{m}$ depth and a second, less pronounced peak at 5,000 m depth (Fig. 5). The respective theoretical distribution differed significantly from this picture, mainly by high and constant anchorage frequencies up to $2,000 \mathrm{~m}$ depth and lower frequencies at greater depths. The distance from the sighted MFADs to the closest port was $31.3 \mathrm{~km}$ on average and showed a strong peak between 20 and $35 \mathrm{~km}$, ranging between 3.2 and $67 \mathrm{~km}$. 

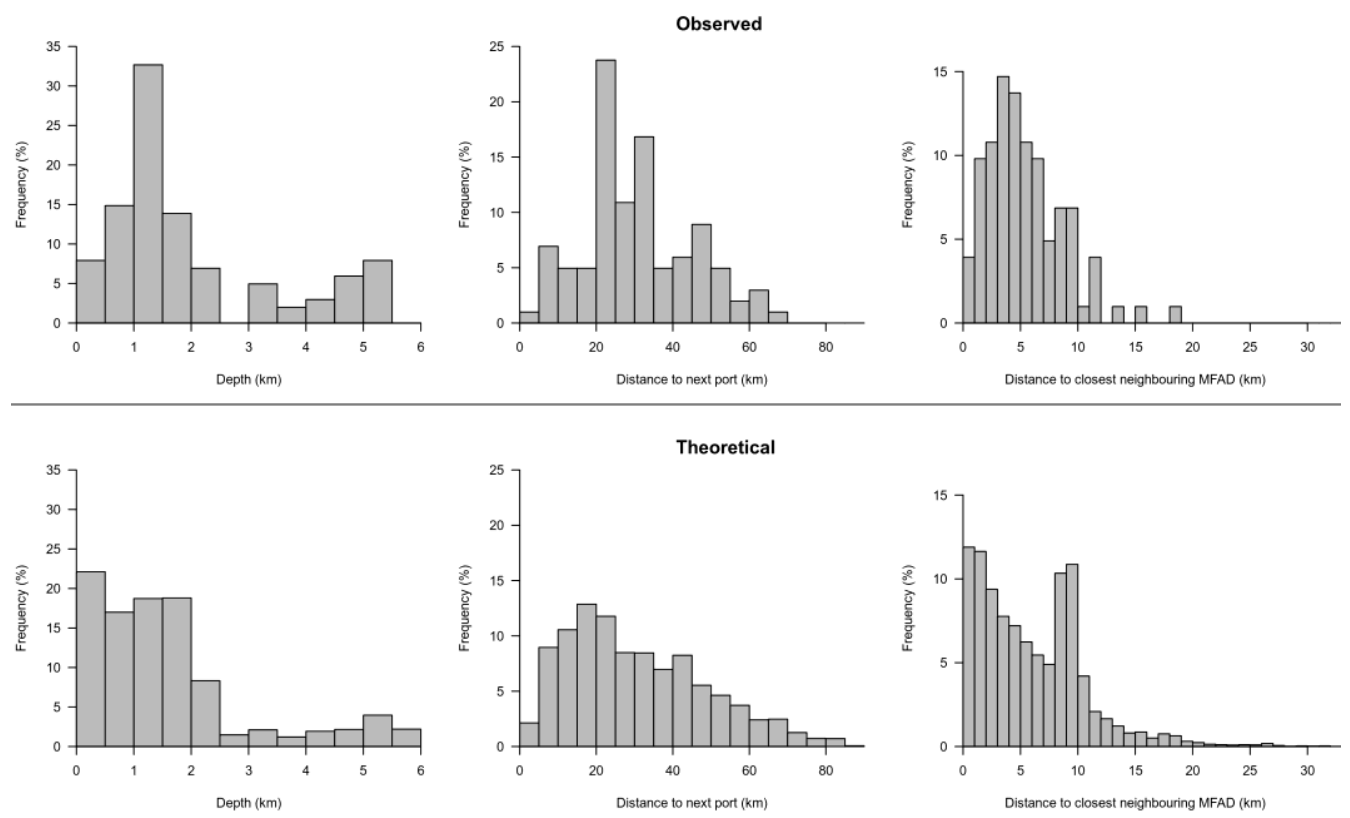

Fig. 5. Observed and theoretical anchorage depth, as well as distances to nearest port and closest neighbouring MFAD.

The theoretical distribution obtained from the sampled transect points was rather rightskewed. In fact, only $17.4 \%$ of sighted MFADs were located within a distance of less than 20 $\mathrm{km}$ from the nearest port, compared with $35 \%$ of the transect points. The average distance between sighted MFADs was $5.6 \mathrm{~km}$, following a normal distribution (SD: $3.6 \mathrm{~km}$ ). However, relatively few MFADs (3.8\%) were located within a distance of less than $1 \mathrm{~km}$ from the next closest MFAD. This contrasts with the theoretical distribution based on encounter rates, which showed a continuous decrease in frequencies with distance, but also a second peak at around $9 \mathrm{~km}$ corresponding to cases where the closest MFAD was located on the neighbouring transect (inter-transect distance of $8.9 \mathrm{~km}$ ). 


\section{Discussion}

In this study, we provide the first estimates of MFAD densities obtained through aerial line transect surveys. Around 2.1 MFADs per $100 \mathrm{~km}^{2}$ were located in late 2012 in the waters around Guadeloupe. While temporal changes in MFAD densities cannot be excluded (e.g., due to loss of MFADs and the deployment of new MFADs by fishermen), spatial differences in the location of MFAD deployment sites were evident, in accordance with fishing effort data from the area. MFAD densities and fishing effort were especially high in the area east of Guadeloupe. This data also suggests that fishing effort, and thus MFAD density, might be low in the area south of Guadeloupe, from which survey results (18 December 2012) gave the same indication but could not be included in the analysis due to unsuitable weather conditions (Tab. 1). However, areas located even further to the east (> $30 \mathrm{~km}$ ), for which reported fishing effort from MFAD fishing was particularly high, could not be surveyed. The estimated density and abundance of MFADs in waters around Guadeloupe is therefore likely higher than calculated and this non-surveyed area probably contains 100-200 additional MFADs.

Distance sampling modelling (i.e. the modelling of the detection probability per perpendicular distance) relies on the assumption that all objects of interest on the transect line were detected. This assumption may not always apply in the field, as objects might not be visible to the observer (e.g., due to submergence; availability bias). Objects could also be missed by observers, even when visible and thus detectable. Possible reasons for this "perception bias" include distraction, fatigue and lack of experience, but also environmental conditions such as sea state. While availability bias can be considered to be of minor 
importance, given that MFADs are always floating at the surface, perception bias may apply. This bias is usually assessed with double-observer platforms using mark-recapture distance sampling (MRDS; Borchers et al., 1998). However, since no such platform was available to us during the aerial surveys, perception bias could not be assessed.

Another, more common, sampling practice in aerial surveys where the positions of sighted objects are not directly measured is to back-calculate perpendicular distances to sighted objects from sighting angles and aircraft altitude (Beavers et al., 1998; Andriolo et al., 2006). Here, sighting angles are measured by an inclinometer while the object of interest is abeam the aircraft. This method requires additional handling time by the observer, making it less applicable for aerial surveys, which are conducted at a high travelling speed, where objects can pass through the detection range within a few seconds, sometimes in swift succession. A comparison on the accuracy of these two sampling methods is given in Marques et al. (2006).

A recent study indicated that vessels regularly operate on MFADs located at $80 \mathrm{~km}$ from the eastern ports of Guadeloupe (Guyader and Frangoudès, 2015). Most of these MFADs are anchored on the island shelf at depths of 1000-3000 m, but some have been reported beyond these depths. In agreement with these results, our sighted MFADs were deployed across a broad range of depth; but they were also found at rather greater distances from the coast. In particular, high MFAD densities were found in the north-eastern part of the surveyed area, in waters of $4000-5000 \mathrm{~m}$ deep. In this area, MFADs are exposed to stronger currents and, therefore, mainly consist of large mono-buoys designed to increase FAD buoyancy against the currents. The observed selection of deeper and thus more distant 
deployment locations likely represents a strategy to avoid unwanted access by other fishermen to private MFADs, which are seen as fishing territories in a context of strong competition between fishermen (Guyader and Frangoudès, 2015). In fact, the relatively short distance between MFADs $(91.3 \%<10 \mathrm{~km})$ indicates a severe overdeployment, by which fishermen increase the risk of reducing the attractiveness and productivity of their own MFADs.

A number of different factors could explain the current MFAD spatial distribution around Guadeloupe. As reported by Diaz (2007), the first MFADs were placed close to the coast, at distances of $10 \mathrm{~km}$ from fishing ports, but increasing competition between fishermen has gradually encouraged MFAD deployment in more distant areas with higher anchorage depths and consequent higher MFADs installation costs and harvesting costs. The spatial distribution of target species likely represents another factor of influence. In this regard, Reynal et al. (2015) showed that yields per fishing trip for MFADs in Martinique increased with distance from the coast, including for yellowfin tuna, the main target species of MFAD fisheries in the Caribbean. The same may apply in Guadeloupe, where yellowfin tuna are caught using the same technique (drifting vertical longlines). Hence, MFAD deployment strategies may result from a trade-off between expected revenues (higher yields) and costs (higher fuel and MFADs costs with the distance to fishing ports). Other factors such as species targeting strategies, gears used or MFAD fishing territories may also be considered as they have been observed in other MFAD fisheries (Aprieto 1991; Dickson and Natividad, 2000; Christy, 1982; Morales et al., 2000). 
MFAD density has rarely been studied. Our results therefore represent an important reference value. In fact, a similar aerial line transect survey was carried out by the authors in December 2012 in Martinique, $190 \mathrm{~km}$ to the south of Guadeloupe. However, it was not possible to accurately estimate MFAD density and abundance around Martinique due to the low number of MFADs sighted and the incompleteness of the area covered (No surveys could be conducted to the east of Martinique). In any case, the results of this "unpublished" survey indicate an encounter rate of 0.006 MFADs per $\mathrm{km}$ of transect ( 5 detections for 831.5 km of effort; Fig. S1), which is very low compared with Guadeloupe (Tab. 1) (See Reynal et al., 2007, for past assessment of the MFAD distribution in Martinique).

The comparatively low number of FADs around Martinique is surprising as the amount of fishing vessels and effort appears to be quite similar in these two regions (Mathieu et al., 2013). It is interesting to note that most MFAD detections (76\%) in Guadeloupe were made in areas of less than $3000 \mathrm{~m}$, while the survey effort in the waters off Martinique mostly covered this depth level. However, MFAD deployment is not necessarily restricted by depth, and a high density area of MFADs NE of Guadeloupe was located in waters of around $4000 \mathrm{~m}$ depth. In fact, fishing strategies on MFADs differ between these areas, which could provide an explanation for the rather low MFAD densities in Martinique. As highlighted by Guyader et al. (2011), fishing trips in Guadeloupe are characterized by successive visits (nomadism) to a large number (5-15) of MFADs during a fishing trip. A visit is usually associated with a particular fishing operation, but the time spent fishing on individual MFADs is limited by the fact that fishermen visit several MFADs within a trip, targeting mainly dolphinfish. This kind of fishing behaviour differs significantly from Martinique, where fishermen typically remain most of the day around one MFAD targeting mainly tunas (Reynal et al., 2007). 
Nomadism between a relatively large number of MFADs can be explained by the characteristics of the targeted resources, mainly dolphinfish, which are rare even in fish aggregations around FADs, unlike tunas (Taquet, 2004). When fishermen catch dolphinfish, they harvest the entire amount around a FAD. The competition between fishermen targeting dolphinfish thus encourages them to deploy more MFADs over a larger area to increase their chances. Some fishermen, who experienced the beginning of MFAD deployment, recognized that they caught more tuna with less MFADs, but mentioned that fishing dolphinfish in large numbers requires more MFADs (Guyader and Frangoudès, 2015). High numbers of MFADs have also been reported in dolphinfish MFAD fisheries in the Mediterranean (Morales et al., 2000).

Guyader and Frangoudès (2015) also revealed evidence for territoriality in relation to MFAD deployment in the north-eastern part of the Guadeloupe fishing area around La Désirade Island. The MFADs of each fishing vessel are positioned by following virtual lines, defining a course from a particular point on the island, usually the main port or the point of anchorage of a fishing vessel along the coast. Each line represents a few degrees' difference from its neighbours. Almost all of the space is occupied within an $80-\mathrm{km}$ radius of the island. The number of MFADs per fishing vessel varies between 5 and 20 and most fishermen consider their MFAD lines as exclusive territories, with little or no cooperation between fishermen for sharing MFADs. However, Guyader and Frangoudès (2015) noted that respect of the exclusive use of MFAD territories is difficult because the areas concerned are very extensive and difficult to monitor. As a consequence, it was reported that some fishermen operate on MFADs they encounter or have noticed during their previous fishing trips. 
As indicated earlier, higher MFAD densities can lead to aggregation interaction or competition between neighbouring MFADs, with a potential loss in local productivity/catchability (Taquet et al., 2011). Several authors estimated the attraction area of FADs to be 7 to 13 km (Cayré and Chabanne, 1986; Holland et al., 1990; Cayré, 1991; Kleiber and Hampton, 1994). Dagorn et al., (2000) studied the effects of individual behaviour on tuna aggregations around FADs based on a modelling approach, and analysed the effects of the distance between FADs and their network structure on the number of fish aggregated around the FADs. Their results showed that for all the different ranges of FAD influences tested, and whatever the type of network, maximum fish aggregation is obtained when the attraction areas of FADs do not overlap. They concluded that, regardless of the FAD influence range between 3.6 and $18 \mathrm{~km}$, deploying FADs at inter-FAD distances $\geq 22.3 \mathrm{~km}$ yielded highest numbers of fish aggregated by FAD network. This value corresponds to the $20.5 \mathrm{~km}$ proposed by Holland et al. (1990) and Cayré (1991) as the minimizing dilution of fish resources between adjacent FADs. The model of Dagorn et al. (2000) also suggests that the higher the FAD influence range, the greater the interest of increasing the distance between FADs in order to avoid dilution. According to these figures, 0.3 MFADs per $100 \mathrm{~km}^{2}$ would be required, while we estimated that seven times more MFADs were in place at the end of 2012. However, recommendations for MFAD density are valid mainly for tuna species, which are significant in the catches (20\%), but not necessarily for dolphinfish (65\% of total catches), for which FADs may not have the same range of influence. 


\section{Towards sustainable MFAD management}

As mentioned earlier, the network of collective MFADs established in 2008-2009 was not successful and few of these MFADs were still in place by 2012 when our aerial surveys were carried out. The main reason suggested by fishermen's organisations for this failure was the financial difficulties encountered in the care and maintenance of these devices. Guyader and Frangoudès (2015) concluded that collective MFADs were established in areas where the estimated number of private MFADs was extremely high. They also indicated that some of them were installed in parts of the territorial area where, because some of the informal territories had been established for more than 20 years, certain fishermen considered fishing these areas as their historical right. As a consequence, the acceptability of collective MFADs by fishermen was generally low, especially in areas of high MFAD density and acts of vandalism were committed against collective MFADs in some areas. Commitment to collective MFADs has been limited, with the exception of some of the fishing communities in southwestern Guadeloupe, who are involved in the co-management of the network. Even in this case, a significant number of fishermen considered that the number of collective MFADs was insufficient and that device surveillance was too low (Guyader et al., 2008). Conversely, most of the fishermen considered that the number of private MFADs in place is excessive (Guyader and Frangoudès, 2015); the main reasons given were ecological, economic and social. From an ecological point of view, fishermen consider that MFADs cause a "barrier" effect by blocking fish at sea or slowing down or changing their migration closer to the coast. Some fishermen who experienced the beginning of MFADs recognize that they previously caught more tuna with less MFADs but also mention that fishing dolphinfish requires more MFADs. Fishermen also report that the cost of maintaining a private park of MFADs has 
increased due to the increase in overall MFAD number and installation depths. This raises questions about whether the costs of additional MFADs would outweigh their benefits and what would be the required number and density of MFADs. The issue is also a social one as the privatization of MFAD territories fosters conflicts between fishermen for access to fishing areas.

A number of alternative solutions could be considered, such as the destruction of MFADs or their expropriation. Destruction is currently being considered by the maritime public authorities but would require significant effort for its impact to be effective. Indeed, MFADs can be quickly reinstalled by fishermen, with the risk that MFAD camouflage methods would then be developed to avoid identification and tracking, even by aerial surveys. Expropriation is not possible as there is no right of ownership. The withdrawal of a concession or occupation of territory is only possible if MFADs have been declared, while most are in fact illegal. In the light of the failure of the collective MFAD projects, one possible strategy could be to establish a larger degree of convergence between politically decided management objectives and what fishermen perceive as legitimate, by adjusting the management regime (Nielsen, 2003). The legalization of established informal territories could represent such a possibility (Christy, 1982) and could actually incorporate a maximum of the currently deployed MFADs. As advocated by Christy (1982), a core issue in the decision to create territorial use rights is to foster community management, while defining the community that will receive the rights and responsibilities of management.

One of the difficulties in Guadeloupe is to strengthen fishing communities in the comanagement of MFAD territories. Community-based management may help to significantly 
improve the regulatory process, as fishermen and managers work together and thus contribute to its success (Johannes et al., 2000). However, Gutierrez et al. (2011) identified strong leadership and social capital as the most important attributes contributing to the actual success of fisheries co-management. In the context of co-management, scientists may have a particularly important role to play by assessing the biological and socio-economic effects of a reduction in the number of MFADs. Regarding the densities of MFADs and related spatial variations, it would be particularly interesting to study the potential interactions between MFAD densities, fish aggregations and fishing yields. As suggested by Moreno et al. (2015), MFADs could be instrumented so as to use them as scientific platforms with the possibility of equipping buoys with echo-sounders to estimate fish abundance independent from the fishery (Robert et al., 2013). As similar results to those obtained by Dagorn et al. (2000) can be expected from such a study, its organisation in collaboration with local fishermen could actually help to encourage fishermen to reduce their number of MFADs. Geo-location of all vessels fishing on MFADs may be an additional means to identify and track the position of a large number of MFADs, as Guyader et al. (2011) and Alvard et al. (2015) show that appropriate processing of information on vessel trajectories may be a way to locate MFADs. This information could also be useful to more accurately monitor the intraannual and inter-annual variations in the number of MFADs, but this type of approach has never been implemented at a large scale. 


\section{Conclusion}

Our results indicate that aerial surveys provide a useful tool to obtain fishery-independent density estimates of MFADs. Repetitions of the aerial surveys, conducted on a regular basis, could help us to monitor the implementation and success of MFAD management regulations. Survey repetitions could further help to reinforce detection frequency patterns and thus help improve estimates of detection probabilities and MFAD densities. Despite the lack of available data on the size of area influenced by MFADs with regard to dolphinfish aggregation, the MFAD density estimates obtained here seem too high for this species, which is the main one targeted, and most of the fishermen consider the number of MFADs as excessive. However, reducing the number of deployed MFADs is not simple, as shown by a prior unsuccessful attempt to set up collective MFADs in the Guadeloupe area. Successful experiences of other MFADs fisheries around the world could also be applied to improve MFADs governance in Guadeloupe.

\section{Acknowledgements}

The authors would like to thank C. Dromer, V. Morra V., S. Gréaux, L. Timor, W. BrinDesnoue, C. Pau and M. Bouaziz for their contribution to the aerial surveys in Guadeloupe. This work was funded by the MAGDELESA project on sustainable development of fishing on moored fishing aggregating devices in the Lesser Antilles. The MAGDELESA project was cofinanced under the INTERREG IV Caribbean program and ERDF. 


\section{References}

Alvard, M., Carlson, D., McGaffey, E., 2015. Using a Partial Sum Method and GPS Tracking Data to Identify Area Restricted Search by Artisanal Fishers at Moored Fish Aggregating Devices in the Commonwealth of Dominica. PLoS ONE, 10(2), :e0115552. doi:10.1371/journal.pone.0115552

Amandé, M., Ariz, J., Chassot, E., Delgado de Molina, A., Gaertner, D., Murua, H., Pianet, R., Ruiz, J., Chavance, P., 2010. Bycatch of the European purse seine tuna fishery in the Atlantic Ocean for the 2003-2007 period. Aquat. Living Resour. 23, 353-362.

Amante, C., Eakins, B. W. 2009. ETOPO1 1 Arc-Minute Global Relief Model: Procedures, Data Sources and Analysis NOAA Technical Memorandum NESDIS NGDC-24, 19 pp. https://www.ngdc.noaa.gov/mgg/global/relief/ETOPO1/docs/ETOPO1.pdf

Andriolo, A., Martins, C. C. A., Engel, M. H., Pizzorno, J. L., Más-Rosa, S.; Freitas, A. C., Morete, M. E., Kinas, P. G., 2006. The first aerial survey to estimate abundance of humpback whales (Megaptera movaeangliae) in the breeding groung off Brazil (Breeding Stock A). J. Cetacean Res. Manag. 8, 307-311.

Anderson, J., Gates, P.D., 1996. South pacific commission fish aggregating device (FAD) manual Volume I planning FAD programmes, South Pacific Commission, New Caledonia,46p.

http://www.spc.int/DigitalLibrary/Doc/FAME/Manuals/Anderson 96 FAD Vol1.pdf

Aprieto, V.L., 1991. Payao, tuna aggregating device in the Philippines.In Artificial reef and Fish Aggregating Devices as tools for the management and enhancement of marine 
fishery resources. Indo-Pacific Fishery Commission, Colombo, Sri Lanka, 14-17 May 1990, RAPA-FAO-UN 1991/11, 14-15. $\underline{\text { bin/faobib.exe?rec id=344177\&database=faobib\&search type=link\&table=mona\&ba }}$ ck path=/faobib/mona\&lang=eng\&format name=EFMON

Bauer, R.K., Bonhommeau, S., Brisset, B., Fromentin, JM., 2015. Aerial surveys to monitor bluefin tuna abundance and track efficiency of management measures. Mar. Ecol. Prog. Ser. 534, 221-234.

Bauer R., 2016. oceanmap: A plotting toolbox for 2D oceanographic data. R package version 0.0.1, https://CRAN.R-project.org/package=oceanmap

Beavers, S. C., and F. L. Ramsey. 1998. Detectability Analysis in Transect Surveys. J. Wild. Manage., Wiley on behalf of the Wildlife Society $62,948-957$

Borchers, D. L., Zucchini, W., Fewster, R. M., 1998. Mark-Recapture Models for Line Transect Surveys. Biometrics 54(4), 1207-1220.

Buckland, S. T., 2001. Introduction to Distance Sampling: Estimating Abundance of Biological Populations. Oxford University Press.

Buckland, S. T.; Anderson, D. R.; Burnham, K. P.; Laake, J. L.; Borchers, D. L., Thomas, L., (Eds.) 2004. Advanced Distance Sampling Ecology, Oxford University Press.

Cayré, P., 1991. Behaviour of yellowfin tuna (Thunnus albacares) and skipjack tuna (Katsuwonus pelamis) around fish aggregating devices (FADs) in the Comoros Islands as determined by ultrasonic tagging. Aquat.Living Resour. 4, 1-12. 
Christy, F., 1982. Territorial use rights in marine fisheries: Definitions and conditions. FAO Fisheries Technical Paper No 227. 573

http://www.fao.org/docrep/003/T0507E/T0507E00.HTM (accessed March 2015).

CRFM Fishery Report 2010. Fishery Management Advisory Summaries, Report of Sixth Annual Scientific Meeting - Kingstown, St. Vincent and the Grenadines, 07 - 16 June 2010.

http://mail.crfm.net/ uwohxjxf/images/Report $f$ the Sixth Annual Scientic Meetin

g - Volime 2.pdf

CRPMEM de La Réunion 2015. Dispositifs de Concentrations de Poissons - État du Parc - 01 juin 2015. http://www.crpmem.re/024-dcp

Dagorn L., Josse,E., Bach, P., Bertrand, A., 2000. Modeling tuna behaviour near floating objects: from individuals to aggregations. Aquat. Living Resour. 13, 203-211

Dagorn, L., Holland, K. N., Restrepo, V., Moreno, G., 2012. Is it good or bad to fish with FADs? What are the real impacts of the use of drifting FADs on pelagic marine ecosystems? Fish. Fish. 14, 391-415.

Davies, T.K., Mees, T.C., Milner-Gulland, E.J., 2014. The past, present and future use of drifting fish aggregating devices (FADs) in the Indian Ocean. Marine Policy 45, 163-170

Dempster, T., Taquet, M.,2004. Fish aggregation device (FAD) research: gaps in current knowledge and future directions for ecological studies. Reviews in Fish Biology and Fisheries 14, 21-42. 
Diaz, N., Druaut-Aubin, V., Frangoudes, K., Guyader, O., Knockaert, C., Le Roy, Y., Nelson, L., Reynal, L., Walters, R., Lagin, A., Rivoalen, J. J., 2005. Main Results from the Work Completed by the "Lesser Antilles" Working Group on the Sustainable Development of Moored FADs Fishing and Perspectives. -In Proceedings of the Fifty Eighth Annual Gulf and Caribbean Fisheries Institute- San Andres Colombia. pp. 237-244 http://procs.gcfi.org/details_view.php?datalD=2390 (accessed August 2015).

Diaz, N., 2007. Rapport national de Guadeloupe: Le dispositif de concentration de poissons ancrés artisanal léger guadeloupéen, In: Report of the Second meeting of the WECAFC Ad-hoc Working Group on the Development of Sustainable Moored Fish Aggregating Device Fishing in the Lesser Antilles, Bouillante, Guadeloupe, 5-10 July 2004. FAO $\begin{array}{llllll}\text { Fisheries Report. No 797. Rome, FAO.2007. } & \text { 232. }\end{array}$ http://wwz.ifremer.fr/carafad/Themes/Resources-ecosystems-and-fishing

Dickson, J., Natividad, A.C., 2000. Tuna fishing and a review of payaos in the Philippines. In Pêche thonière et dispositifs de concentration de poissons, eds. J-Y. Le Gall, P. Cayré, and M. Taquet,. pp. 141-158. Ifremer, Actes Colloq. 28. http://archimer.ifremer.fr/doc/00042/15284/ (accessed March 2015).

Doray, M., Josse, E., Gervain, P., Reynal, L., and Chantrel, J., 2006. Acoustic characterisation of pelagic fish aggregations around moored fish aggregating devices in Martinique (Lesser Antilles). Fisheries Research 82, 162-175.

Fortuna, C. M., Kell, L.,Canese, S., Mackelworth, P., Donovan, G. 2014. Summer distribution and abundance of the giant devil ray: baseline data for an iterative management framework. Scientia Marina 78, 227-237. 
Fonteneau, A., Chassot, E., Gaertner, D., 2015. Managing tropical tuna purse seine fisheries through limiting the number of drifting fish aggregating devices in the Atlantic: food for thought. Collect. Vol. Sci. Pap. ICCAT, 71(1): 460-475

Gervain, P., Reynal, L., Defoe J., Ishida M., 2015. Manual of best practices in fisheries that use Fish aggregating devices (FADs), Vol. I Fad design, construction and deployment, December 2015, CRFM Secretariat, Belize

Gervain P., Diaz N., 2011. Parc de DCPs collectifs de Guadeloupe (technologie, surveillance, entretien). Communication to the FADs conference, Tahiti, November 2011.

Gomes, C., Mahon, R., Hunte, W., Singh-Renton, S., 1998. The role of drifting objects in pelagic fisheries in the Southeastern Caribbean. Fisheries Research 34, 47-58.

Guyader, O., Reynal, L., Angin, B., Beramice D., Erialc, C., Cedric, J-C., Vincent, C., 2008.Contribution à l'évaluation de l'impact de l'implantation des DCP collectifs sur l'activité de pêche en Guadeloupe. Rapport final. http://archimer.ifremer.fr/doc/00190/30108/

Guyader O., Reynal L., Berthou P., Leblond E., Bellanger M., Campéas A., Angin B., Quemener L., Pitel-Roudaut M., 2011. Exploring fishermen behaviour around moored FADs: the example of air plane surveys and vessels positioning system in Guadeloupe and Martinique. Communication to the FADs conference, Tahiti, November2011.

Guyader, O., M. Bellanger, L. Reynal, S. Demaneche, Berthou. P., 2013. Fishing strategies, economic performance and management of moored fishing aggregating devices in Guadeloupe. Aquat. Living Resour. 26, 97-105 
Guyader, O., Reynal, L., Lespagnol, P., Le Meur, C., Demaneche, S., Le Blond, S., Jean-Charles, C., Erialc, C., Rulle, L., Bourgeois, P., Cornou, A. S., Leblond, E., Merrien, C., Le Ru, L., Blanchard, F., Daures, F., Berthou, P., 2014. Synthèse des pêcheries de Guadeloupe 2012. http://sih.ifremer.fr/Publications/Syntheses/Outre-Mer/Guadeloupe/Synthesedu-quartier/2012

Guyader, O., Frangoudès, K., 2015. Territoriality and territorial use rights opportunities for moored fishing aggregating devices: Example of small-scale fisheries in La Désirade Island (Guadeloupe). Amure working paper series, R39-2016. http://www.umramure.fr/pg electro rap.php

Gutierrez, N.L., Hilborn, R., Defeo, O., 2011. Leadership, social capital and incentives promote successful fisheries. Nature 470, 386-389.

Hijmans, R.J. 2015. geosphere: Spherical Trigonometry.R package version 1.3-13. http://CRAN.R-project.org/package=geosphere

Holland, K.N., Brill, R.W., Chang, R.K.C., 1990. Horizontal and vertical movements of yellowfin and bigeye tuna associated with fish aggregating devices. Fish. Bull. U.S. 88, 493-507.

ICCAT, 2014. Compendium management recommendations and resolution adopted by ICCAT for the conservation of Atlantic tunas and tuna-like species. https://iccat.int/Documents/Recs/ACT COMP 2014 ENG.pdf (accessed August 2015)

Johannes, R.E., Freeman, M.M.R. and Hamilton, R.J. 2000. Ignore fishers' knowledge and miss the boat. Fish and Fisheries 1, 257-271. 
Kleiber, P., Hampton, J., 1994. Modelling effects of FADs and islands on movement of skipjack tuna (Katsuwonus pelamis): estimating parameters from tagging data. Can. J. Fish. Aquat. Sci. 51, 2642-2653.

Marques, F. F. C., Buckland, S. T. 2004. Covariate models for the detection function. In and S. T. Buckland, D. R. Anderson, K. P. Burnham, J.L. Laake, D.L. Borchers (Ed.), Advanced Distance Sampling (pp. 31-47). Oxford University Press.

Marques, T. A., Andersen, M., Christensen-Dalsgaard, S., Belikov, S., Boltunov, A., Wiig, O., Buckland, S. T., Aars, J., 2006. The use of Global Positioning Systems to record distances in a helicopter line-transect survey. Wildlife Society Bulletin 34, 759-763

Mathieu, H., Reynal., L., Magloire A., Guyader, O., Does FAD deployment have a real effect on fishing redeployment towards offshore resources? Proceedings of the 66th Gulf and Caribbean Fisheries Institute November 4 - 8, 2013 Corpus Christi, Texas USA, $511-517$

Ministry of Fisheries and Agriculture, 2015. Overview of FAD Implementation of Maldives.

\section{http://www.fishagri.gov.mv/index.php/en/fisheries/fad-center}

Morales-Nin, B. Cannizaro, L., Massuti, E., Potoschi, A., F. Andaloro.F., 2000. An overview of the FADs fishery in the Mediterranean Sea, In: Pêche thonière et dispositifs de concentration de poissons, eds. J-Y. Le Gall, P. Cayré, and M. Taquet, pp. 184-207.

Moreno, G., Dagorn, L., Capello, M., Lopez, J., Filmater, J., Forget, F., Sancristobal, I., Holland, K. 2016. Fish Aggregating Devices (FADs) as scientific platforms. Fisheries Research $178,122-129$ 
Nielsen, J. R., 2003. An analytical framework for studying: compliance and legitimacy in fisheries management. Mar. Policy 27, 425-432

Prefectural Order of $2002 \mathrm{~N}^{\circ} 2002 / 1249$ of 19 th August regulating the coastal marine fisheries in the waters of the Guadeloupe department, Section III article 47.

Ramdine, G., 2007. Synthèse sur les systèmes de gestion des dispositifs de concentration de poisons dans les Petites Antilles en 2004, In: Report of the Second meeting of the WECAFC Ad-hoc Working Group on the Development of Sustainable Moored Fish Aggregating Device Fishing in the Lesser Antilles, Bouillante, Guadeloupe, 5-10 July 2004. FAO Fisheries Report. No 797. Rome, FAO.2007. pp. 126-137.

Rey-Valette, H., Cillaurren, E., David, G., 2000. Multidisciplinary assessment of the sustainability of small-scale fishery around anchored FADs. Aquatic Living Resources 702(13), 241-252.

Reynal, L., Chantrel, J. Lagin, A. 2007. La pêche associée aux dispositifs de concentration de poissons ancrés et sa localisation autour de la Martinique: premiers éléments de description, In: Report of the Second meeting of the WECAFC Ad-hoc Working Group on the Development of Sustainable Moored Fish Aggregating Device Fishing in the Lesser Antilles, Bouillante, Guadeloupe, 5-10 July 2004. FAO Fisheries Report. No 797. Rome, FAO.2007. pp. 191-204.

Reynal, L., Guyader, O., C. Pau, C. , H. Mathieu, H., Dromer, C. 2015. Different means contributing to anchored FAD's fishing selectivity in the Lesser Antilles Collect. Vol. Sci. Pap. ICCAT 71(5), 2297-2301. 
Robert, M., L. Dagorn, J. Lopez, G. Moreno, Deneubourg, J.L. 2013. Does social behavior influence the dynamics of aggregations formed by tropical tunas around floating objects? An experimental approach. J. Exp. Mar. Biol. Ecol. 440, 238-243

Rowat, D., Gore, M., Meekan, M. G., Lawler, I. R., Bradshaw, C. J. A. 2009.Aerial survey as a tool to estimate whale shark abundance trends. Journal of Experimental Marine Biology and Ecology 368(1), 1-8. doi:10.1016/j.jembe.2008.09.001

Taquet, M., L. Reynal, Laurans, M. 2000. Do FADs influence the geographical distribution of dolphinfish (Coryphaena hippurus)? In Pêche thonière et dispositifs de concentration de poissons, eds. J-Y.Le Gall, P. Cayré, and M. Taquet, pp. 528 536. Ifremer, Actes 716 Colloq. 28. http://archimer.ifremer.fr/doc/00042/15321/ (accessed March 2015).

Taquet, M., 2004. Le comportement agrégatif de la dorade coryphène (Coryphaena hippurus) autour des objets flottants. Thèse de Doctorat de I'Université de Paris 6, Océanologie biologique, 168 p.

Taquet, M., Blanc, M., Dagorn, L., Filmalter, J. D.,Fonteneau, A., Forget, F.,Gaertner, J. C., Galzin, R., Gervain, P., Goujon, M., Guillotreau, P., Guyader, O., Hall, M., Holland, K.,Itano, D., Monteagudo, J.P.,Morales-Nin, B., Reynal,L., Sharp, M., Sokimi, W.,Tanetoa, M., Yen Kai Sun, S., 2011. Artisanal and industrial FADs: A question of scale. Tahiti conference reviews current FAD use and technology. Fisheries Newsletter $136,35-45$.

Venables, W. N., Ripley, B. D., 2002. Modern Applied Statistics with S (4th ed.). New York, NY: Springer. 
Worton, B. J., 1989 Kernel Methods for Estimating the Utilization Distribution in HomeRange Studies. Ecology 70(1), 164-168. 


\section{Supplementary material:}

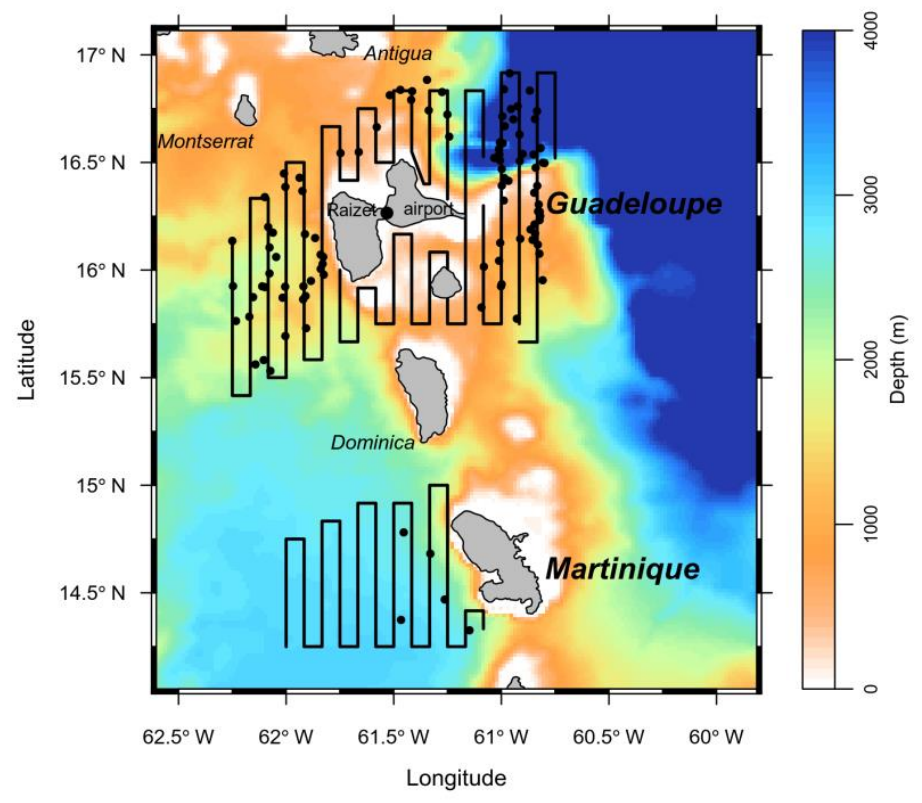

Fig. S1. Transects lines and sighting locations of MFADs (black dots) of aerial surveys conducted around Guadeloupe and Martinique during December 2012. Note that horizontal and diagonal transect lines are off-effort and not considered in the line transect modelling and the estimation of encounter rates. 